\title{
Pleurotus ostreatus spent mushroom substrate for the degradation of polycyclic aromatic hydrocarbons: the case study of a pilot dynamic biopile for the decontamination of a historically contaminated soil
}

\author{
Simona Di Gregorio, ${ }^{\mathbf{a}^{*}}$ Simone Becarelli, ${ }^{\mathrm{a}, \mathrm{b}}$ Giovanna Siracusa, ${ }^{\mathrm{a}}$ Monica Ruffini Castiglione, ${ }^{\mathrm{a}}$ Giulio \\ Petroni, ${ }^{\text {a }}$ Gualtiero Masini, ${ }^{\mathrm{c}}$ Alessandro Gentini, ${ }^{\mathrm{c}}$ Mara Rúbia de Lima e Silva ${ }^{\mathrm{a}, \mathrm{d}}$ and RobertoLorenzi ${ }^{\mathrm{a}}$
}

* Correspondence to: S Di Gregorio, Department of Biology, University of Pisa, Italy. Email: simona.digregorio@unipi.it

${ }^{a}$ Department of Biology, University of Pisa, Italy

${ }^{\mathrm{b}} B D$, Biodigressioni srl, Pisa, Italy

${ }^{\mathrm{c}}$ Teseco SpA, Pisa, Italy BD, Biodigressioni srl, Pisa, Italy

${ }^{\mathrm{d}}$ Department of Hydraulics and Sanitation, School of Engineering of São Carlos, University of São Paulo, Brazil

\begin{abstract}
BACKGROUND: Polycyclic aromatic hydrocarbons (PAHs) are hazardous contaminants. Bio-based technology is among recommended practices for the recovery of PAH contaminated matrices. The objective of the study was to validate the exploitation of spent mushroom substrate (SMS), an organic waste deriving from the industrial production of Pleurotus ostreatus, as bulking agent in a dynamic biopile pilot plant, because of the SMS potential oxidative capacity towards aromatic recalcitrant compounds. The dynamic biopile pilot plant treated 7 tons of a historically PAH contaminated soil (6469 $\pm 423 \mathrm{mg}$ PAHs kg-1), classified as dangerous waste.

RESULTS: The mixing of SMS with soil was mandatory for the depletion of PAHs, which after 8 months, were at significantly lower concentrations $(112 \pm 5 \mathrm{mg}$ PAHs $\mathrm{kg}-1)$. The treated soil was capable of reintroduction to the industrial site of origin. However, a residual genotoxicity of soil elutriates at the end of the process was measured on root tips of Vicia faba L.

CONLUSIONS: The SMS derived from the industrial production of $P$. ostreatus is exploitable as a versatile low cost organic substrate with oxidative capacity towards PAHs and its exploitation as a bulking agent in biopiles is advantageous for the disposal of the organic waste.
\end{abstract}

Keywords: $\alpha$ subunit (RHD $\alpha$ ) aromatic ring hydroxylating dioxygenases; dynamic biopile; genotoxicity; Pleurotus ostreatus; polycyclic aromatic hydrocarbons; spent mushroom substrate; Vicia faba L 


\section{INTRODUCTION}

Polycyclic aromatic hydrocarbons (PAHs) are a large group of organic contaminants principally deriving from anthropogenic sources such as uncompleted combustion of fossil fuels, natural combustions and volcanic eruptions, but with the majority due to anthropogenic emissions such as automobile exhausts, processing production and accidental spillage of petroleum. Numerous studies indicated that low molecular weightPAHs with one, two, or three rings are acutely toxic, and high molecular weight types with more than three rings are genotoxic. $1-3$ Due to their low water solubility, high hydrophobicity and recalcitrance to biodegradation, PAHs tend to accumulate in the soil organic matter. High concentrations of PAHs in soils and sediment cause significant hazards to many organisms including humans. ${ }^{4,5}$ Despite their low bioavailability, biodegradation is the principal process affecting the fate of PAHs in the environment. The bacterial oxidation of PAHs depends on hydroxylation of the PAH ring, which is essential to prime the oxidation and the depletion of PAHs in the environment. ${ }^{6}$ The reaction consists of incorporation of molecular oxygen into the PAH aromatic nucleus by the multicomponent aromatic ring hydroxylating dioxygenase (RHD) enzyme. The enzyme is composed of large $\alpha$ and small $\beta$ subunits. ${ }^{7}$ The large $\alpha$ subunit (RHD $\alpha$ ) contains two conserved regions: the Fe2-S2 Rieske centre and the mononuclear iron-containing catalytic domain. Homologous RHD $\alpha$ subunits, encoded by phylogenetically distant genes, have been cloned in both Gram positive (GP) and Gram negative (GN) bacterial species. ${ }^{8}$ The presence of these genes is generally considered as representing the PAH biodegradation potential of environmental matrices, and, in soils and sediments, their quantification is proportional to the level of PAH contamination. ${ }^{6}$ Fungi were also described as capable of biodegrading PAHs; namely, the high molecular weight fraction. Fungi, besides intracellular metabolism of PAHs due to cytochrome P450 activity, oxidize PAHs by the extracellular ligninolytic enzyme battery. 9,10 In fact, ligninolytic enzymes have low substrate specificity, which enables them to degrade a wide range of organic pollutants, including PAHs. ${ }^{9}$ The main ligninolytic enzymes are the multi-copper oxidases, the laccases, and the Mn dependent and $\mathrm{Mn}$ independent peroxidases. Lignin-degrading fungi were exploited to deplete PAHs in soil with efficacy. 11 14 Among the fungal ligninolytic enzymes, the one produced by Pleurotus ostreatus was described as capable of transforming a very broad spectrum of waste substrates $15-17$ comprising PAHs. 18 In this context, it is worth mentioning that $P$. ostreatus is an edible mushroom and its industrial cultivation produces a significant amount of spent mushroom substrate (SMS), reported as harbouring high levels of residual oxidative enzymatic activity. ${ }^{19}$ The ability of spent substrates from the industrial production of edible fungi and their inherent microbiota to biodegrade different contaminants containing PAHs was reported. ${ }^{20}$ At the same time, soil PAH contamination is characteristic of large portion of the territory hosting industrial activities. A biobased intervention for their decontamination, to be consistent, must deplete the recalcitrant PAH contamination 
in a period of time compatible with the continuity of the human activities, respecting both health and environment. Most of the time ex situ (off site or on site) interventions are the choice of the regulators. Dynamic biopiles are consolidated ex situ plant configurations based on the control and eventual elicitation of the microbial biodegradation of the contamination. Although the process may vary slightly for each batch of contaminated material received, general processes are undertaken: the contaminated matrix is stockpiled on the biopad and it is eventually mixed with surfactant, organic additives and a nitrogen source. Stockpiles are then incubated, turning with an excavator on a regular basis to allow air into the stockpiles that favor oxidative reactors. Stockpile soil testing is undertaken on a regular time basis to measure the progress of the oxidative process. The process is repeated until validation samples show that the soil has been successfully decontaminated. Remediated soil can be returned to sites where the contaminated soil has been sourced from, to allow for the backfilling of excavations, or it can be remediated at a level that allows its re-use in other public sites. Dynamic biopiles are the sites of process that can be generally defined as an oxidative process, with a significant oxygen demand. For this reason, most of the time, the soil texture is improved by amendment with a lignocellulosic bulking agent that increases aeration of the soil. Consequently the aim of this work was both the validation of the SMS from $P$. ostreatus as a versatile low cost organic substrate with oxidative capacity, whose reutilization as bulking agent in a biopile is sustainable in terms of costs and the eventual profitability for the design of an integrated management of the disposal of the SMS as an organic waste. In fact, the aim of this study was to verify the efficiency of the SMS to promote the depletion of PAHs from a historically contaminated soil. The soil, due to the high level of

contamination ( $6469 \pm 423 \mathrm{mg}$ PAHs kg-1), was classified as dangerous waste. To determine the efficiency of the bioremediation treatment a pilot scale experiment was adopted, treating 7 tons of contaminated soil using the SMS as bulking agent in a dynamic biopile. The efficacy of the strategy was evaluated by measuring PAH depletion. During the process of decontamination, the chemical data were accompanied by evaluation of the changes in the microbial community structure, with reference to the different bacterial taxaand the fungal biodiversity. Thelevels of transcription of the bacterial Gram positive and Gram negative PAH-RHD $\alpha$ genes encoding the enzymes priming the PAH oxidation were quantified. Toxicological assessment of the safety of the decontaminated soil was performed at the end of the process by monitoring the genotoxicity of soil elutriates on the model plant Vicia faba L..

\section{MATERIALS ANDMETHODS}

\section{Chemicals and soil}

Chemicals used throughout the experiments were of analytical grade and purchased from Sigma-Aldrich (Milan, Italy). Chemical standards of the 16 PAHs including naphthalene (NA), acenaphthylene (ACY), acenaphthene (ACE), fluorene (FL), phenanthrene (PH), anthracene (AN), fluoranthene (FLU), pyrene (PY), benzo a anthracene $(\mathrm{BaA})$, chrysene $(\mathrm{CH})$, benzo b fluoranthene $(\mathrm{BbF})$, benzo k fluoranthene $(\mathrm{BkF})$, benzo a pyrene $(\mathrm{BaP})$, indeno 1,2,3-cd pyrene (IP), dibenzo a, h anthracene (DA), and benzo g,h,i perylene (BP), the deuterated 
PAH internal standard solutions (naphthalene-d8, acenaphthene-d10, phenanthrene-d10, chrysene-d12, and perylene-d12), and surrogate standard solutions (2-fluorobiphenyl and 4-terphenyl-d14) were obtained from AccuStandard Chem. Co. (USA). Internal and surrogate standards were used for sample quantification and process recovery. The PAH contaminated soil was provided by Teseco SpA (Pisa, Italy). The texture of the soil was sandy (35\% silt, $50 \%$ sand, and $15 \%$ clay) with total phosphorous of $1.5 \%$ and total nitrogen of $1.3 \%$.

\section{Experimental condition}

At laboratory scale experiment a total of nine experimental replicates (glass pots), each containing $1000 \mathrm{~g}$ of soil

$\left(6469 \pm 423 \mathrm{mg} \mathrm{PAHs} \mathrm{kg}^{-1}\right)$, were prepared and maintained in a temperature controlled $\left(21 \pm 1^{\circ} \mathrm{C}\right)$ dark chamber at $60 \%$ soil maximum water holding capacity ( $\mathrm{WHC}_{\max }=9.6 \%$ dry mass). Three mesocosms out of nine were mixed with $20 \%$ on a weight base ratio with SMS derived from the industrial production of $P$. ostreatus. Three microcosms were mixed with autoclaved SMS $\left(121 \pm 1{ }^{\circ} \mathrm{C}, 1 \mathrm{Atm}\right)$. Three mesocosms were not mixed with SMS. All pots were routinely manually mixed every 3 days of incubation and checked for water content. After 4 months incubation, the pots were sacrificed and analysed for PAH content. At pilot scale experiment a total of 7 tons of contaminated soil $\left(6469 \pm 423 \mathrm{mg} \mathrm{PAHs} \mathrm{kg}{ }^{-1}\right)$ was mixed in a tank (length $\times$ width $\times$ height, $6.2 \times 2.1 \times 1.5$ m) with $20 \%$ on a weight base ratio of SMS derived from the industrial production of P. ostreatus. 1 ton of the same soil, not mixed with SMS, was prepared in a separate tank as a control. The tanks were equipped with a system to recover soil elutriates. The soil in the two tanks was adjusted to $60 \%$ of soil maximum water holding capacity. The two tanks were managed as two dynamic biopiles and monitored and maintained by the industrial partner Teseco SpA by controlling the water content, which was maintained at $60 \%$ of soil $\mathrm{WHC}_{\max }$ by the re-use of soil elutriates, eventually integrated with tap water. The biopiles were prepared in December and closed in August and mechanically mixed every week. Soil samples were obtained by collecting columns of soil from the biopiles every half square meter grid using a stainless steel probe. The collected columns of soil were roughly mixed together and divided into four technical replicates. Routinely, three of them were separately extracted and analyzed for chemical analytical data (PAH content), for biochemical data (ergosterol content) for molecular data (taxonomical and functional molecular markers). Soil samples from biopiles were collected every month.

\section{PAH extraction and analytical procedures}

Soil samples collected from the mesocosms and the biopiles were dried in a vented oven at $25{ }^{\circ} \mathrm{C}$ for $36 \mathrm{~h}$. All samples were extracted using a soxhlet apparatus with 1:1 (v/v) acetone/n-hexane. A total of $10 \mu \mathrm{L}$ of surrogate standard mixture (2-fluorobiphenyl and 4-terphenyl-d14) solutions were added. The concentration of the surrogates was $250 \mathrm{ng} \mathrm{mL}^{-1}$ each. Method blanks were prepared following the same procedure without adding a soil sample. Verification of the calibration for quality control was prepared by adding the standard solution to 1:1 (v/v) acetone $/ n$-hexane at a concentration equal to $75 \%$ of the last calibration point. After subsequent drying over 
anhydrous sodium sulphate of the organic fraction and concentration to $1.0 \mathrm{~mL}$ using a gentle stream of nitrogen, an internal standard mixture (naphthalene-d8, acenaphthene-d10, phenanthrene-d10, chrysene-d12, and perylened12) solution at a final concentration of $50 \mathrm{ng} \mathrm{mL}^{-1}$ each was added to the extract to be analyzed using gas chromatography with mass selective detection (GC-MS). The internal standard mixture was selected to cover all the fragmentation ranges of the 16 analyzed PAHs. The quantitative analysis of PAH was performed with an Agilent 6890 GC-5975B Series MS system in the selective ion monitoring mode (SIM). Injection of $1 \mu \mathrm{L}$ of samples was conducted in the splitless mode with a sampling time of $1.0 \mathrm{~min}$. Separation of PAH congeners was carried out with a $30 \mathrm{~m}$ (long) $\times(0.25 \mathrm{~mm}$ inner diameter) HP-5MS capillary column (Hewlett-Packard, Palo Alto, CA, USA) coated with 5\% phenyl-methylsiloxane (film thickness $0.25 \mu \mathrm{m}$ ). The injection temperature was $300{ }^{\circ} \mathrm{C}$. The transfer line and ion source temperatures were $280{ }^{\circ} \mathrm{C}$ and $200{ }^{\circ} \mathrm{C}$, respectively. The column temperature was initially held at $40^{\circ} \mathrm{C}$ for $1 \mathrm{~min}$ and raised to $120^{\circ} \mathrm{C}$ at the rate of $25^{\circ} \mathrm{Cmin}^{-1}$, then to $160^{\circ} \mathrm{C}$ at the rate of $10{ }^{\circ} \mathrm{C} \mathrm{min}^{-1}$, and finally to $300{ }^{\circ} \mathrm{C}$ at the rate of $5^{\circ} \mathrm{C} \mathrm{min}^{-1}$, and held at final temperature for $15 \mathrm{~min}$. Detector temperature was kept at $280^{\circ} \mathrm{C}$. Helium was used as carrier gas at a constant flow rate of 1 $\mathrm{mL} \mathrm{min}^{-1}$. Identity of the PAHs in the samples was confirmed by retention time and the relative abundance of selected monitoring ions of the standard PAHs. The 16 priority PAHs were quantified using the response factors related to the respective internal standards based on five-point calibration curves for each individual compound ranging from $10 \mathrm{ng} \mathrm{mL}^{-1}$ to $1000 \mathrm{ng} \mathrm{mL}^{-1}$. Each PAH concentration was corrected using the recovery rate of the surrogate standard and expressed on a dry-weight basis.

\section{Ergosterol extraction and analysis}

Total ergosterol was extracted and analyzed as described by Sna- jdr et al. ${ }^{21}$ Samples of soil were sonicated at 70 ${ }^{\circ} \mathrm{C}$ for 90 min with a methanolic solution of $\mathrm{KOH}(10 \%$, w/v). Afterwards the samples were extracted three times with cyclohexane. The solvent was evaporated under a nitrogen stream and the solid residue dissolved in $1 \mathrm{~mL}$ methanol. Aliquots of the methanol solution were analyzed by reversed-phase high performance liquid chro- matography (RP-HPLC) equipped with a LiChroCART ${ }^{\circledR} 250$ - 4 LiChrospher ${ }^{\circledR} 100$ RP-18 (5 $\mu \mathrm{m})$ equilibrated with $100 \%$ methanol at a flow rate of $1 \mathrm{~mL} \mathrm{~min}^{-1}$. The elution profile was monitored at 282 $\mathrm{nm}$. Limit of detection (LOD) and limit of quantification (LOQ) were determined with a series of dilute solutions of referencestock solution.

\section{Molecular techniques}

The total DNA from soil was purified using the FastDNA ${ }^{\mathrm{TM}}$ SPIN Kit for Soil, following the manufacturer's instructions. Quantitative real-time PCR was applied to assess the community structure at the level of taxonomic 
group by quantifying the relative abundance of different bacterial taxa. Quantitative real-time PCR was applied also to quantify the copy number of the bacterial Gram positive and Gram negative PAH-RHD $\alpha$ genes encoding the enzymes priming the PAH oxidation. Taxa specific 16S rDNA primers were used for quantification of the Actinobacteria, Acidobacteria, $\alpha$ - and $\beta$-Proteobacteria, Bacteroidetes and Firmicutes. Primers used are described in Table 1. PCR reactions were carried out on an ABI Prism ${ }^{\circledR} 7300$ Sequence Detection System using Sybr ${ }^{\circledR}$ Green PCR Master Mix (Applied Biosystem, Monza, Milan, Italy). The presence of PCR inhibitors was estimated by diluting the metagenomic DNA and by mixing a known amount of standard DNA with the metagenomic DNA prior to quantitative real-time PCR. No inhibition was detected in both cases. For each reaction, approximately $2 \mathrm{ng}$ of DNA was used as template, forward and reverse primers were used at a 0.6 mmol L-1 final concentration, and water to a final volume of $50 \mu \mathrm{L}$. Samples were always measured in triplicate. Cycling condition consisted of an initial denaturation at $95^{\circ} \mathrm{C}$ for $10 \mathrm{~min}: 40$ cycles, denaturation at $95^{\circ} \mathrm{C}$ for $15 \mathrm{~min}$ and annealing-extension at $54-60{ }^{\circ} \mathrm{C}$ for $1 \mathrm{~min}$. After this step, acquisition took place. A melting curve ranging from 50 to $99{ }^{\circ} \mathrm{C}$ was performed with steps of $1{ }^{\circ} \mathrm{C}$ and a hold of 5 s to check the specificity of the assays. For each $16 \mathrm{~S}$ rRNA target, a standard curve was established using serial dilutions of linearized plasmid pGEM-T ( $10^{2}$ to $10^{7}$ copies) containing cloned $16 \mathrm{~S}$ rDNA. The linearized plasmid for GN PAHRHD $\alpha$ quantification was constructed by cloning the corresponding purified PCR product from Pseudomonas putida G7 DSM 50222. For GP PAHRHD $\alpha$ and 16S rDNA quantification, the linearized plasmids were constructed by cloning the corresponding PCR products from Mycobacterium vanbaalenii DSM 7251. Two no-template controls (NTC) were also included in all the assays. At each run, two standard curves per sample were included and all the samples were related to the corresponding standard curve. Amplification efficiencies were calculated from the slopes of the standard curves. ${ }^{30}$ To confirm the specificity of each of the primer sets, samples from the first run using the primer set were loaded onto a $2 \%$ agarose gel. Primer sets did not yield any side products in low copy number dilutions and in NTCs. The amplification levels of taxa-specific genes were first normalized by the amplification level of $16 \mathrm{~S} \mathrm{rDNA} .31,32$ The fractional copy number of each taxa was calculated as the ratio between the normalized amplification lev els for each taxa in soil mixed with the SMS and in soil not mixed with theSMS. All theresults were computed with ABIPrism7300 software v1.3.1.

PCR - DGGE (polymerase chain reaction denaturing gradient gel electrophoresis) was used to analyze and compare the fungal communities that developed during the treatment in the pilot plant. The analysis was based on the separation of 300-400 bp long ITS1 amplification products. FungalrDNAinternal transcribed spacer (ITS1) regions were amplified in triplicate for each DNA extract with the fungal-specific primers ITS1f-gc 33 and ITS2. 34 The PCR reaction was $95{ }^{\circ} \mathrm{C}$ for 10 min denaturation; 38 cycles of $94{ }^{\circ} \mathrm{C}$ for $45 \mathrm{~s}$, annealing at $56{ }^{\circ} \mathrm{C}$ for $45 \mathrm{~s}$, extension at $72{ }^{\circ} \mathrm{C}$ for $90 \mathrm{~s}$; final extension at $72{ }^{\circ} \mathrm{C}$ for $10 \mathrm{~min}$. Denaturing gradient gel 
electrophoresis (DGGE) was carried out with a DCode Universal Mutation Detection System (BioRad, USA) using $8 \%(\mathrm{w} / \mathrm{v})$ acrylamide:bis-acrylamide (37.5:1) gels with $25 \%\left(10 \%(\mathrm{v} / \mathrm{v})\right.$ formamide, $1.75 \mathrm{~mol} \mathrm{~L}^{-1}$ urea) to $55 \%\left(22 \%(\mathrm{v} / \mathrm{v})\right.$ formamide $3.85 \mathrm{~mol} \mathrm{~L}^{-1}$ urea) linear gradients of denaturants. Gel electrophoresis was performed in a $1 \mathrm{X}$ TAE buffer at $60{ }^{\circ} \mathrm{C}$ at $75 \mathrm{~V}$ for $17 \mathrm{~h}$. The gels were stained for $30 \mathrm{~min}$, washed in $1 \mathrm{X}$ TAE solution for 5 min and photographed under UV light using the Gel Doc imaging system (Bio-Rad, Germany).

\section{Genotoxicity tests}

Seeds of V.faba L., following a procedure previously described, 35 were germinated at $24 \pm 1{ }^{\circ} \mathrm{C}$ for $72 \mathrm{~h}$ in soil elutriates. Soil elutriates were prepared 36 starting from soil samples collected from both the biopiles as previously described. The soil elutriates of the biopile not mixed with the SMS and of the biopile mixed with the SMS were compared with negative controls, achieved using distilled water. Ten roots for each treatment were fixed in ethanol:glacial acetic acid $(3: 1 \mathrm{v} / \mathrm{v})$. Root tips were squashed and stained following the Feulgen technique. ${ }^{37}$ At least 1000 nuclei, randomly selected for each slide, were analyzed by means of a light microscope for estimation of the mitotic activity, mitotic aberrations and the micronuclei frequency. Mitotic activity, expressed as mitotic index MI (number of mitosis per 100 nuclei), indicated the levels of cytotoxicity of the matrices. Micronucleus frequency assay (MNC test, number of micronuclei per 1000 nuclei), and mitotic aberrations (aberration index $\mathrm{AI}=$ number of aberrations per 100 nuclei) were determined for evaluation of the genotoxicity of the matrices.

The categories of the scored aberrations included chromosomal bridges and fragments, lagging chromosomes, aberrant metaphases and disturbed anaphases in dividing cells, micronuclei in interphase cells. 38

\section{Statistical analysis}

All the data were elaborated with the aid of ANOVA and means were separated by Fisher's least significant ( $P$ difference (LSD) test 0.05) using the specific software Statgraphics 5.1 (Statistical Graphics Corp., USA). 


\section{RESULTS}

\section{PAHs depletion}

The quantification of PAH content in mesocosms after 4 months of incubation indicated a decrease of $15.2 \%$ and of $11.6 \%$ in the mesocosms not mixed with SMS and the mesocosm mixed with autoclaved SMS, respectively. The PAHcontent in the mesocosms mixed with the SMS recorded a decrease of the $57.8 \%$.

The pilot dynamic biopiles were maintained for PAH depletion for 8 months. During the 8 months of incubation, the total PAH content in the dynamic biopile not mixed with the SMS varied within $10-15 \%$ of the initial value. On the other hand, in the soil mixed with the SMS, 50.6\% PAH depletion was observed during the first month of incubation (Table 2). In detail, during the first month of incubation $78.3 \%$ depletion of two condensed rings naphthalene was observed. The percentages of depletion of the three condensed rings PAHs spanned from zero to $46.6 \%$ for anthracene. The percentages of depletion of the four condensed rings PAHs spanned from $52.7 \%$ to $61.8 \%$ for pyrene. The percentages of depletion increased for the five and six condensed rings PAHs spanning from 79\% for indeno 1,2,3-cd pyrene up to $100 \%$ for benzo-a-pyrene, with the exception of benzo-k-fluorantene (2.8\% depletion). After the first month of incubation, $50.6 \%$ depletion of total PAHs was observed. On the other hand, after 2 months of incubation $72 \%$ depletion of total PAHs was observed, with an increase in percentage depletion of the three condensed rings PAHs with reference to the four condensed rings PAHs. 100\% depletion of benzo-k-fluorantene and indeno 1,2,3-cd-pyrene was also observed, even though an increase in the concentration of naphthalene and benzo-b-fluoranthene was also measured. At the third and fourth month of incubation the percentages of depletion of the three condensed rings PAHS was higher than that observed for the four condensed rings PAHs, with respect to the previous month of incubation. At the fourth month of incubation $100 \%$ depletion was observed for benzo $b$ fluoranthene. At the same time, $76.2 \%$ depletion of total PAHs was observed. At the fifth month of incubation 97.6\% depletion of total PAHs was observed and the percentage depletion of the single PAHs spanned from $81.2 \%$ to $100 \%$, with the exception of $47.9 \%$ for benzo a antrhracene and $48.1 \%$ for chrysene, which persisted to the end of the experiment, corresponding with $97.9 \%$ depletion of total PAHs (Table 2).

\section{Fungal growth and community structure}

The quantification of ergosterol in the two biopiles revealed that a variation in sterol content was observed only in the biopile mixed with the SMS (Fig. 1). The ergosterol content of the contaminated soil (CTRL) increased in the presence of the SMS (T0). However during the time of incubation in the pilot plant the level of ergosterol decreased starting from the first month of incubation and stabilized after the second month of incubation at concentration 1.8 times higher than in the CTRL, with the exception of the sixth month of incubation, when the ratio between the ergosterol concentrationin the soil in treatment andin the CTRL was 1.5. 
The molecular profiles of the fungal community in the soil, during the treatment, were investigated by DGGE analysis of the PCR amplified ITS1 fragment obtained by analysis of the metagenome of the microbial community characterizing the soil in treatment at the different times of analysis. Results are shown in Fig. 2 where the image of one of the DGGE gels is reported. The contaminated soil was characterized by a fungal community composed of different dominant taxonomy units (DGGE bands) that were reduced to a dominant unit at the time of the mixing of the soil with the SMS. At successive times of analysis the biodiversity of the dominant fungal taxonomy units increased, as indicated by theincrease of the number of DGGE bands recovered in the different lanes of the gel. At the same time, the increase in fungal biodiversity was accompanied by changes in the phylogenetic distribution of the dominant taxonomy units (strongly stained DGGE bands) during the process of decontamination. A stabilization of the phylogenetic distribution of the dominant taxonomy units was observed at times of analysis T3 and T4. The DGEE profiles were normalized and analyzed by cluster analysis, and the Shannon Weaver biodiversity index and Eveness value were calculated (Table 3). Results obtained showed that biodiversity of the fungal community did not change in the control biopile during the 8 months of experiment, as well as the distribution (Eveness value) of the fungal candidate among the different taxa. Mixing of the soil with the SMS determined a decrease of the biodiversity as well a decrease of the equal distribution of fungal candidates among the different taxa. Both the Shannon Weaver index and the Eveness values varied during the 8 months of experimentation. After an increase of the parameters during the first 2 months of incubation a decrease of the corresponding indexes was observed at times $\mathrm{T} 3$ and $\mathrm{T} 4$ of analysis. Further fluctuations were recorded at successive times of analysis. After 8 months of treatment the biodiversity of the fungal community was lower than in the sediment before mixing with the SMS.

\section{Bacterial community structure}

Quantification of the GP and GNPAH-RHD $\alpha$ transcripts was normalized to the levels of transcription of the 16S rDNA representing the dominant bacterial community structure. Results are shown in Fig. 3. GP and GN PAHRHD $\alpha$ transcripts were both detected in the contaminated soil (CTRL). Any increase in the two transcript was observed in the soil of the biopile not mixed with the SMS. At the same time, in the biopile mixed with the SMS, an increase in the GP and GN PAH-RHD $\alpha$ transcripts was observed during all successive times of analysis. The GP PAH-RHD $\alpha$ transcript increased nearly twice as much as the GN PAH-RHD $\alpha$ at time of analysis T5. This difference increased with successive times of analysis.

The Acidobacteria, $b$-Proteobacteria, Actinobacteria, $a$-Proteobacteria, Bacteroidetes, and Firmicutes were also quantified during the treatment of soil in the pilot plant, by normalizing them to the levels of transcription of the $16 \mathrm{~s}$ rDNA representing the dominant bacterial community structure. Results obtained are shown in Fig. 4. The taxonomic bacterial groups analysed were all detected in the contaminated soil, but their fractional copy numbers were not affected in the soil not mixed with the SMS. In fact, all the bacteria taxa that were quantified in the 
present experiments increased with mixing of the soil with the SMS. In general a higher increase was observed for the Actinobacteria and the Firmicutes, which at the end of the experiment were, respectively, 18.4 and 49.1 times the fractional copy number at the beginning of the experiment. More precisely, Actinobacteria increased in fractional copy number starting from the time of the mixing of the soil with the SMS (T0). A successive increase was observed, even though the increase was statistically significant only after the third month of incubation and actually stabilized at the final values at the fifth month of incubation. On the other hand, the fractional copy number of the Firmicutes increased progressively from the time of mixing of the contaminated soil with the SMS, with a statistically significant increase recorded at the fourth month up to the sixth month of incubation, when the Firmicutes fractional copy stabilized at the final values.

As a general result an increase in the fractional copy numbers of the different bacterial taxa was observed with and after mixing the soil with SMS. Stabilization of the fractional copy number for all the bacterial taxa, with the exception of the Actinobacteria and Firmicutes, occurred after the first month of incubation.

\section{Plant bioassays}

The genotoxicity of the soil elutriate at the end of the treatment was estimated by analysing the frequency of anomalies and/or aberrations in dividing cells and the frequency of micronuclei (MNC) in the interphase of the $V$. faba L. root meristematic cell population. The controls of the experiment were water and the soil elutriates of the soil in the control biopile not mixed with the SMS. Results obtained are reported in Table 4. The soil elutriate of the biopile mixed with the SMS, at the end of the experiment, exerted genotoxic effects on $V$. $f a b a$, detectable as clastogenic and aneugenic damage. In fact, while the mitotic activity of the root in water, quantified as mitotic index was significantly higher than in the soil elutriates, the values of the aberration index and of the frequencies of MNC sharply increased for soil elutriate deriving from the biopile mixed with the SMS compared with values for water and elutriates from the biopile not mixed with the SMS. 


\section{DISCUSSION}

In this study a historically contaminated soil, excavated in a disused petrochemical site, was treated in a dynamic biopile for abatement of PAH contamination, characterized mainly by two, three and four condensed rings molecular structures. Very recalcitrant five and six condensed ring PAHs were also present, although at lower concentrations. With the aim to design a bio-based approach for cost-sustainable depletion of the PAH contamination, microbial biodegradation processes were tentatively adopted. The experiment performed was at pilot scale, treating 7 tons of contaminated soil in dynamic biopiles, where the SMS from P. osteatus was exploited as bulking agent. In fact, the same substrate was previously described as a source of robust ligninolityc enzymes and successfully tested for the discoloration of complex chromobaths for the textile industry. 39 Lignocellulosic amendments to contaminated soil were reported to exert a trophic effect on the autochthonous microbial community. ${ }^{20,40}$ Consequently, the aim of the experiment was to validate the matrix as a versatile low cost organic substrate with oxidative capacity, exploitable as a bulking agent in biopile-like treatment plants.

Since the pilot plant was designed to treat 7 tons of soil, a mesocosms experiment was attempted to optimize the design of the experiment, both in terms of cost sustainability and robustness of results. The main point was to verify the differential effect of mixing the soil with a metabolically inactivated SMS or not mixing the soil with the SMS, in order to design an appropriate control for the pilot scale experiment. Results obtained showed depletion of PAHs by $10-15 \%$ after 4 months of incubation in the absence of SMS and in the presence of a metabolically inactivated SMS. The depletion percentages were not significant in comparison with the depletion recorded in the mesocosms incubated with the SMS. Results obtained indicated that, at least in the time interval analysed, the metabolically inactivated SMS had only a very moderate biostimulatory effect on the microbial community of the soil in terms of PAH degradation.

Due to these results the control biopile was set up in absence of the SMS. However, the biostimulatory effect of the SMS reported by other authors 20,40 cannot be excluded in the present experiment. The only reasonable assertion is that in the time interval of the mesocosms scale experiment, the contribution of the biostimulatory effect to the soil was not sufficient to justify the sterilization of significant amounts of SMS to set up this specific pilot scale experiment.

The SMS here exploited hosts the mycelium of $P$. ostreatus and a non-identified microflora consisting of an uncharacterized fungal and bacterial load that can be involved in the oxidative capacity of the matrix, frequently associated exclusively with the presence of basidiomycetes. In order to tentatively evaluate the role of the fungal load in the process of PAH depletion, the ergosterol content in the soil treated was quantified. Ergosterol is actually a

specific indicator of the fungal biomass. ${ }^{41}$ Results obtained showed that the fungal ergosterol content increased 
significantly with mixing of the soil with SMS. Any increase in the soil ergosterol basal level was monitored in the soil not mixed with the SMS, showing that the lignocellulosic matrix was a vehicle for fungal inoculum. However, observing the progressive decrease in ergosterol content in the pilot biopile during the decontamination of the soil, it is reasonable to assume that the process is accompanied by the establishment of stress conditions for the fungal community. On the other hand, in relation to the DGGE analysis of the soil fungal community, results showed a diversified population of fungal specimen in the contaminated soil. This latter persisted unchanged in terms of diversity and distribution in the soil not mixed with SMS, as indicated by the Shannon Weaver index and the Eveness value. Conversely, instability, for both fungal specimen diversity and their distribution among different dominant populations, was observed during the decontamination process. Also this recorded instability can be associated with the establishment of stress conditions for the fungal community. Both the decrease in fungal load and the instability in terms of fungal species diversity is reasonably consistent with the toxic effect eventually exerted by high content in PAHs. Moreover, a toxic effect can be reasonably exerted by the accumulation of intermediates of PAH degradation that can be as toxic as or even more toxic than the parent chemical structures. In relation to this assessment the changes in the speciation of the dominant fungal populations during the process of decontamination evidenced by the DGGE profile and the variation in the Eveness values, might be related to the progressive speciation of different fungal population resistance and/or capable of oxidative activity towards the accumulating plethora of different and unknown intermediates of degradation of PAHs. In fact, results obtained, within the limit of the analytical method adopted, eventually subjected to PCR bias, ${ }^{42}$ showed a fungal community in continuous evolution during the 8 month incubation, very far from the stabilization during the treatment. At the time of mixing the soil with the SMS, a single dominant fungal phylum was detected on the gel. It is reasonable to assume that the result is an artefact presumably imposed by the efficiency of the primers used in the PCR reaction that, even though not described for preferential target amplification, in the present experimental conditions, reasonably amplified only a very limited number of fungal specimen. The bias was particularly evident at the time of the mixing of the soil with the SMS because of the evidence that both the soil and the SMS were harbouring diverse fungal specimen. However, associated with the mixing of the soil with the SMS, a reduction in biodiversity and distribution among the different phyla of the fungal specimen was observed also at times T3 and $\mathrm{T} 4$ and eventually at T7. At the remaining time of analysis a higher biodiversity with respect to the control was observed. The fluctuation of the values related to the biodiversity of the fungal load during the process can be the result of an equilibrium between the toxicity of both the parental contaminants, their intermediates of degradation and eventually their bioavailability.

In relation to PAH depletion, it is interesting to note that the five and six condensed rings PAHs were depleted by the third month of incubation (T3), positively correlating with the highest content in ergosterol during the experiment. No evident correlation between depletion of the PAH high molecular fraction and the DGGE analysis can be assumed. However, it is worth mentioning that while ergosterol is a robust biochemical 
marker for metabolic active fungal load, all the analysis performed at genomic level on a metagenome are not necessarily referred to the metabolic active portion of the microbial community analysed. Consequently, it is reasonable to assume that the positive correlation between the ergosterol soil content and PAH high molecular weight fraction depletion, is actually an indication of a possible role of the fungal fraction in depletion of the five and six condensed rings PAHs. In fact, ligninolytic fungi have been reported to play an important role in PAH degradation in natural environments, particularly in the initial degradation of the high molecular weight PAHs. ${ }^{43}$ Some authors suggest that in the synergistic metabolic activity of fungi and bacteria in a microbial population degrading PAHs, the fungal metabolizing activity is the source of intermediates of PAH degradation that actually are further metabolized by bacteria. ${ }^{44}$ On the other hand, a bacterial intervention in the depletion of the five and six condensed rings PAHs, cannot be excluded, even though in the present experiments the bacterial load increased significantly later, with respect to the fungal load, when depletion of the PAH high molecular weight fraction had already occurred. In this context, it is worth mentioning that after mixing with SMS, the bacterial load of the soil increased, with a peculiar nearly immediate effect on the Actinobacteria. These latter are particularly abundant in the SMS of P. ostreatus (data not shown) and it is reasonable to assume that the SMS was the vehicle not only for fungal but also for bacterial inoculation. Even though, due to the origin of the SMS, the capacity of the microbial candidates to deplete PAHs was unexpected, some authors 20 observed both a trophic effect of lignocellulosic matrices on PAH degrading bacteria and the presence of PAH degrading bacteria in the spent mushroom substrate from the industrial production of Agaricus. In these terms the SMS can be considered an organic waste exploitable both as a source of macronutrients and eventually micronutrients that favours the autochthonous microflora, as well as a source of allochthonous but eventually competent microbial candidates, for metabolic activities of interest.

In the experiments described here the PAH degrading bacteria abundance was enumerated in terms of copy number of genes priming the oxidation of PAHs, the large $\alpha$ subunit of the multicomponent aromatic ring hydroxylating dioxygenase (RHD), encoded by phylogenetically distant Gram positive (GP) and Gram negative (GN) genes. At the third month of analysis (T3) the sum of the two fractional copy numbers of the two genes, GP $\mathrm{RDH} \alpha$ and GN $\mathrm{RDH} \alpha$, was significantly higher than at the previous times of analysis (T2) and continued its increase, eventually specifically associated with the $\operatorname{GPRDH} \alpha$. This increase positively correlated with the increase in the Gram positive Actinobacteria and Firmicutes with respect to the Gram negative candidates. Significant increase in the fractional copy number of both the Gram positive RHD $\alpha$ and of the Gram positive Actinobacteria and Firmicutes were recorded at the fifth month of treatment (T5), time of analysis corresponding to $89.9 \%$ PAH depletion with respect to the fourth month of incubation (T4). In summary, the $97.6 \%$ of PAH depletion was already occurred at the fifth month of incubation (T5) with a first decrease of the 50.6\% during the first month(T1) and of the $72 \%$ after 2 months of incubation (T2). These times of analysis positively correlated with the highest content in ergosterol and with the lowest fractional copy number of both the different groups of bacteria and the 
genes encoding for the RHD $\alpha$ subunit. On the other hand between the second (T2) and the fourth month (T4) of incubation the percentage depletion with respect to the initial value remained around $70 \%$ with a significant decrease of the yield of the process of PAH depletion. This latter significantly increased between the fourth (T4) and fifth month(T5) of incubation that was actually the time of analysis that evidenced a significant increase in the fractional copy numbers of both the Gram positive RHD $\alpha$ and of the Gram positive Actinobacteria and Firmicutes. In fact, even though the autochthonous bacterial community clearly possessed the potential for PAH degradation, as evidenced by the presence of genes encoding for the RHD $\alpha$ subunit from both Gram positive and Gram negative bacteria in the contaminated soil, the Gram positive fraction responded to a greater extent to the SMS stimulation. Moreover, the Gram positive fraction was mandatory for recovery in the yield of the oxidative process, determining 89.9\% PAH depletion between the fourth (T4) and fifth (T5) month of incubation. Gram positive bacteria including Actinobacteria and Firmicutes were reported to be dominant PAH degraders in contaminated soil, $45-47$ and Gram positive PAH degraders are reported as dominating in historically PAH contaminated sites. ${ }^{48}$ They are also reported as $k$-strategists that compete for the biodegradation of more persistent PAHs because of their capacity to increase their bioavailability. 49,50 It is reasonable to assume that the decrease in the yield of the oxidative processes, that occurred between the third (T3) and the fourth (T4) month of incubation, was ascribable to the low bioavailability of the residual aged PAHs. In this context the capability of the Gram positive degraders to increase the PAH bioavailability can be interpreted as mandatory for the recovery in the oxidation process efficiency between the fourth (T4) and the fifth (T5) month of treatment, time interval corresponding to the increase of the fractional copy number of the Gram positive RHD $\alpha$ transcripts and of Actinobacteria and Firmicutes. Moreover, Actinobacteria and Firmicutes has been described as involved in the cocomposting of PAHs with agricultural wastes; 51 Firmicutes were described as capable of degrading PAH molecules with up to five fused benzene rings 52 and among Actinobacteria some members (Mycobacterium, Rhodococcus and Gordonia) are described as capable of PAH mineralization. 53

However, in this context it is worth mentioning that the time of instauration of the dominant bacterial specimen,with reference to both taxonomical and functional traits, is reasonably related to the co-occurrence of both PAHs and their intermediates of degradation. The presence of these latter, presumably conserving most of the chemical structures that determine the recalcitrance to biodegradation of the parental molecules, mainly aromatic rings, might be consistent with both the quantification of relative abundance of the different bacterial taxa and of the enzymes priming the PAHoxidation here recorded.

After the fifth (T5) month of treatment the PAH depletion process resulted to be very slow and not transferable at an industrial scale. In fact, the process can be considered halted at the fifth month of incubation (T5), time of analysis actually corresponding to the possibility to reintroduce the soil in the site of origin, according to the domestic regulations and the limits of PAHs content in soils in industrial sites. 
With the aim to validate the hypothesis of a safe reintroduction of the decontaminated soil in the environment, a toxicological assessment of the process of decontamination of the matrix at the end of the process was adopted. Results obtained showed the genotoxicity of the elutriate deriving from the soil at the end of the treatment. The results obtained indicated that the process of decontamination of the soil is at the source of the recorded genotoxicity. This is because of the evidence that the biopile not mixed with the SMS, even though classified as a dangerous matrix and showing a nearly conserved high PAH concentration for the time span of the experiment, showed a reduced genotoxicity of the elutriates with reference to that of the soil at the end of the process of decontamination. As a conclusion, the chemical assessment of the depletion of the PAHs, was inefficient to assess the process of detoxification of the decontaminated soil. In fact, bioassays provide important information for the estimation of pollutant-effects of chemicals on environmental matrices and, complement chemical analyses. In contrast to chemical analyses, bioassays provide direct measurements of impacts of pollutants on the environment and on living organisms. ${ }^{54}$ In this specific case study it is reasonable to suggest that the toxicity of the matrix developed during the PAH depletion process is related to the presence of intermediates of degradation of the PAHs that can be responsible both for the genotoxicity of the elutriates and the instability of the fungal load during all the time intervals of the experiment.

Over recent decades ecotoxicological tests were used as supplementary tools to monitor bioremediation of hydrocarbons, both in laboratory and field studies. 55 In light of this, Vicia faba was chosen as biological system providing a large array of endpoints such as phytotoxicity, cytotoxicity and genotoxicity. Recently, the micronucleous assay with $V$. faba was standardized and inserted within guidelines for evaluation of mutagens in freshwaters and sediments from the Italian 'Istituto Superiore di Sanità 56 and the international protocol, ISO 29200.57

\section{CONCLUSIONS}

Spent mushroom substrate derived from the industrial production of $P$. ostreatus can be exploited as a versatile low cost organic substrate with oxidative capacity towards recalcitrantPAHs, whose reutilisation as bulking agent in a biopile is sustainable in terms of costs and eventually profitable for the design of an integrated management of the disposal of the SMS as an organic waste. A further result here obtained is the evidence of toxicity of biobased processes of transformation of PAHs. The identification of putative mutagens eventually derived from the biological transformation of the primary toxic contaminants, or even the monitoring of their increased bioavailability is not sustainable in terms of costs on a real and laboratory scale. Toxicological assessments mustcooccur with the chemical analysis and $V$. faba toxicity assay represents an excellent approach for monitoring the biodegradation processes in relation to the genotoxicity of elutriates of the environmental matrices. 


\section{ACKNOWLEDGEMENTS}

The project was co-financed by Teseco SpA (www.teseco.it) and the Department of Biology of the University of Pisa. The Mara Rubia de Lima e Silva's contribution was supported by the Car- bala Project 2012-2016 MC-IRSES - International research staff exchange scheme (IRSES). The Simone Becarelli's contribution was supported by the Department of Biology and BD, Biodigressioni. 


\section{REFERENCES}

1 Bamforth SM and Singleton I, Bioremediation of polycyclic aromatic hydrocarbons: current knowledge and future directions. J Chem Technol Biotechnol 80:723-736(2005).

2 Ravindra K, Sokhi R and Van Grieken R, Atmospheric polycyclic aro- matic hydrocarbons: source attribution, emission factors and reg- ulation. Atmos Env 13:2895-2921 (2008).

3 Samanta SK, Sing OV and Jain RK, Polycyclic aromatic hydrocar- bons: environmental pollution and bioremediation. Trends Biotechnol 20:243-248 (2002).

4 VanRooij JGM, Bodelier-Bade MM and Jongeneelen FJ, Estimation of individual dermal and respiratory uptake of polycyclic aromatic hydrocarbons in 12 coke oven workers. Br J Ind Med 50:623-632 (1993).

5 MacRae JD and Hall KJ, Biodegradation of polycyclic aromatic hydro- carbons (PAH) in marine sediment under denitrifying conditions. Water Sci Technol 38:177-185 (1998).

6 Cebron A, Norini M, Beguiristain T and Leyval C, Real Time PCR quantification of PAH-ring hydroxylating dioxygenase (PAH-RHD $\alpha$ ) genes from Gram positive and Gram negative bacteria in soil and sediment samples.JMicrobiol Methods 73:148-159(2008).

7 Kauppi B, Lee K, Carredano E, Parales RE, Gibson DT, Eklund H et al., Structure of an aromatic ringhydroxylating dioxygenasenaphthalene 1,2-dioxygenase. Structure 5:571-586(1998).

8 Habe $\mathrm{H}$ and Omori T, Genetics of polycyclic aromatic hydrocarbon metabolism in diverse aerobic bacteria. Biol Biotechnol Biochem 67:225-243 (2003).

9 Bezalel L, Hadar Y, Fu PP, Freeman JP and Cerniglia CE, Initial oxidation products in the metabolism of pyrene, anthracene, fluorene, and dibenzothiophene by the white rot fungus Pleurotus ostreatus. Appl Environ Microbiol 62:2554-2559 (1996).

10 Novotny C, Erbanova P, Sasek V, Kubatova A, Cajthaml T, Lang E et al., Extracellular oxidative enzyme production and PAH removal in soil by exploratory mycelium of white rot fungi. Biodegradation 10:159168 (1999).

11 Covino S, Svobodová K, Kresinová Z, Petruccioli M, Federici F, D’Annibale A et al., In vivo and in vitro polycyclic aromatic hydro- carbons degradation by Lentinus (Panus) tigrinus CBS 577.79. Bioresource Technol 101:3004-3014(2010).

12 Covino S, Cvancarová M, Muzikár M, Svobodová K, D’annibale A, Petruccioli M et al., An efficient PAHdegrading Lentinus (Panus) tigrinus strain: effect of inoculum formulation and pollutant bioavailability in solid matrices. J HazardMater 183:669-678(2010).

13 Li X, Wu Y, Lin X, Zhang J and Zeng J, Dissipation of polycyclic aromatic hydrocarbons (PAHs) in soil microcosms amended with mushroom cultivation substrate. Soil BiolBiochem 47:191-201(2012).

14 Federici E, Giubilei M, Santi G, Zanaroli G, Negroni A, Fava F et al., Bioaugmentation of a historically 
contaminated soil by polychlorinated biphenyls with Lentinus tigrinus. Microbiol Cell Factory 11:35-44(2012).

15 Aggelis G, Iconomou D, Christou M, Bokas D, Kotzailias S, Christou G et al., Phenolic removal in a model olive oil mill wastewater using Pleurotus ostreatus in bioreactor cultures and biological evaluation of the process. Water Res 16:3897-3904 (2003).

16 Rodríguez-Pérez S, Oduardo NG, Savón RCB, Boizán MF and Augur C, Decolourisation of mushroom farm wastewater by Pleurotus ostreatus. Biodegradation 19:519-526(2008).

17 Zhao LH, Zhou JT, Lu H, Zheng CL, Yang YS, Sun HJ et al., Decolorization of cotton pulp black liquor by Pleurotus ostreatus in a bubble- column reactor. BullEnviron Control Toxicol 80:44-48(2008).

18 Dalgado GC, Barta AI and Eymar E, Combination of biochar amendment and mycoremediation for polycyclic aromatic hydrocarbons immobilization and biodegradation in creosote- contaminated soil. J HazardMater 21:259-266(2015).

19 Chiu SW, Law SC, Ching ML, Cheung KW and Chen MJ, Themes for mushroom exploitation in the 21st century: sustainability, waste management and conservation. J Gen Appl Microbiol 46:269 - 282 (2000).

20 Delgado CG, D'Annibale A, Pesciaroli L, Yuta F, Crognale S, Petruccioli M et al., Implications of polluted soil biostimulation and bioaugmentation with spent mushroom substrate (Agaricus bisporus) on the microbial community and polyciclic aromatic hydrocarbons biodegradation. Sci Total Environ 508:20 $28(2015)$.

21 Snajdr J, Valaskova V, Merhautova V, Herinkova J, Cajthaml T and Baldrian P, Spatial variability of enzyme activities and microbial biomass in the upper layers of Quercus petraea forest soil. Soil Biol Biochem 40:2068-2075 (2008).

22 Cebron A, Norini M, Beguiristain T and Leyval C, Real-Time PCR quantification of PAH-ring hydroxylating dioxygenase (PAH-RHD $\alpha$ ) genes from Gram positive and Gram negative bacteria in soil and sediment samples. J Microbiol Methods 73:148-159 (2008).

23 Muyzer G, Dewaal EC and Uitterlinden AG, Profiling of complex microbial populations by denaturing gradient gel-electrophoresis analysis of polymerase chain reaction-amplified genes-coding for $16 \mathrm{~S}$ ribosomal-RNA. ApplEnviron Microbiol 59:695-700(1993).

24 Lane D, 16 s/23 s rRNA sequencing. Goodfellow ESAM, nucleic acid techniques in bacterial systematics. John Wiley, Chichester(1991).

25 Overmann J, Coolen MJL and Tuschak C, Specific detection of different phylogenetic groups of chemocline bacteria based on PCR and denaturing gradient gel electrophoresis of $16 \mathrm{~S}$ rRNA gene fragments. Arch Microbiol 172:83-94 (1999).

26 Barns SM, Takala SL and Kusk CR, Wide distribution and diversity of members of the bacterial kingdom Acidobacterium in the environment. Appl Environ Microbiol 65:1731-1737 (1999). 
27 Stach JEM, Maldonado LA, Ward AC, Goodfellow M and Bull AT, New primers for the class Actinobacteria: application to marine and terrestrial environments. Environ Microbiol 5:828-841 (2003).

28 Manz W, Amann R, Ludwig W, Vancanneyt M and Schleifer KH, Application of a suite of 16S rRNA-specific oligonucleotide probes designed to investigate bacteria of the phylum cytophagaflavobacter-bacteroides in the natural environment. Microbiology 142:1097-1106 (1996).

29 Meier H, Amann R, Ludwig W and Schleifer KH, Specific oligonu- cleotide probes for in situ detection of a major group of Gram-positive bacteria with low DNA G + C content. Syst Appl Microbiol 22:186-196(1999).

30 Pfaff MW, A new mathematical model for relative quantification in real-time RT-PCR. Nucleic Acids Res 29:e45 (2001).

31 Blackwood CB, Oaks A and Buyers JS, Phylum and class specific PCR primers for general microbial community analysis. Appl Environ Microbiol 71:6193-6198 (2005).

32 Fierer N, Jackson JA, Vilgalys R and Jackson RB, Assessment of soil microbial community structure by use of taxon specific quantitative PCR assays. Appl Environ Microbiol 71:4117-4120(2005).

33 Gardes M and Bruns TD, ITS-RFLP matching for identification of fungi. Methods Mol Biol 50:177 186 (1996).

34 White TJ, Bruns T, Lee S and Taylor JW, Amplification and direct sequencing of fungal ribosomal RNA genes for phylogenetics, in PCR Protocols: A Guide to Methods and Applications ed. by Innis MA, Gelfand DH, Sninsky HH and White TJ.New York Academic Press, pp. 315-322 (1990).

35 Giorgetti L, Talouizte H, Merzouki M, Caltavuturo L, Geri C and Frassinetti S, Genotoxicity evaluation of effuents from textile industries of the region Fez-Boulmane, Morocco: a case study. Ecotoxicol Environ Safety 74:2275-2283 (2011).

36 Plumb RH, Procedures for handling and chemical analysis sediment and water samples. Environmental Protection Agency/Corps of Engineers Technical Committee on Criteria for Dredged and Fill Material, Technical Report EPA-CE-81-a Environmental Laboratory, Waterways Experiment Station, Vicksburg, Mississippi (1981).

37 Venora G, Blangiforti S, Ru $\square$ ni Castiglione M, Pignone D, Losavio F and Cremonini R, Chromatin organisation and computer aided karyotyping of Triticumdurum Desf. Cv. Timilia. Caryologia 55:91 - 98 (2002).

38 Ruffini Castiglione M, Giorgetti L, Geri C and Cremonini R, The effects of nano-TiO2 on seed germination, development and mitosis of root tip cells of Vicia narbonensis L. and Zea mays L. J Nano Res 13:2443 - 2449 (2011).

39 Di Gregorio S, Balestri F, asile M, Matteini V, Gini F, Giansanti S et al., Sustainable discoloration of textile chromo-baths by spent mushroom substrate from the industrial cultivation of Pleurotus 
ostreatus. J Environ Protect 1:85-94(2010).

40 Federici E, Giubilei MA, Covino S, Zanaroli G, Fava F, D’Annibale A et al., Addition of maize stalks and soybean oil to a historically PCB-contaminated soil: effect on degradation performance and indigenous microbiota. N Biotechnol 30:69-79(2012).

41 Davis M and Lamar WRT, Evaluation of methods to extract ergosterol for quantitation of soil fungal biomass. Soil Biol Biochem 24:189-198 (1992).

42 Bellemain E, Carlsen T, Brochmann C, Coissac E, Taberlet P and Kauserud H, ITS as an environmental DNA barcode for fungi: an in silico approach reveals potential PCR biases. BMC Microbiol 10:189 (2010).

43 Salvo VS, Gallizia I, Moreno M and Fabiano M, Fungal communities in PAH impacted sediments of Genoa-Voltri Harbour (NW Mediter- ranean, Italy). Marine Pollut Bull 50:553-559(2005).

44 Sack U, Heinze TM, Deck J, Cerniglia CE, Martens R, Zadrazi F et al., Comparison of phenanthrene and pyrene degradation by different wood decaying fungi. Appl Environ Microbiol 63:3919-3925 (1997).

45 de Menezes A, Clipson N and Doyle E, Comparative metatranscriptomics reveals widespread community responses during phenanthrene degradation in soil. Environ Microbiol 14:2577 - 2588 (2012).

46 Meng L and Zhu YG, Pyrene biodegradation in an industrial soil exposed to simulated rhizodeposition: how does it affect functional microbial abundance? Environ Sci Technol 45:1579-1585 (2011).

47 Peng RH, Xiong AS, Xue Y, Fu XY, Gao F, Zhao W et al., Microbial biodegradation of polyaromatic hydrocarbons. FEMS Microbiol Rev 32:927-955 (2008).

48 Uyttebroek M, Breugelmans P, Janssen M, Wattiau P, Joffe B, Karlson U et al., Distribution of the mycobacterium community and polycyclic aromatic hydrocarbons (PAHs) among different size fractions of a long-term PAH-contaminated soil. Environ Microbiol 8:836-847 (2006).

49 Bastiaens L, Springael D, Wattiau P, Harms H, deWachter R, Verachtert H et al., Isolation of adherent polycyclic aromatic hydrocarbon (PAH)-degrading bacteria using PAH-sorbing carriers. Appl Environ Microbiol 66:1834-1843 (2000).

50 Johnsen AR and Karlson U, Evaluation of bacterial strategies to promote the bioavailability of polycyclic aromatic hydrocarbons. Appl Microbiol Biotechnol 63:452-459 (2004).

51 Covino S, Fabianova T, Kresinova Z, Cvancarova M, Burianova E, Filipova A et al., Polycyclic aromatic hydrocarbons degrada- tion and microbial community shifts during co-composting of creosote-treated wood. J HazardMater 301:17-26(2016).

52 Haritash AK and Kaushik CP, Biodegradation aspects of polycyclic aromatic hydrocarbons (PAHs): a review. J Hazard Mater 169:1-15 (2009).

53 Antizar-Ladislao B, Spanova K, Beck AJ and Russell NJ, Microbial community structure changes 
during bioremediation of PAHs in an aged coaltar contaminated soil by invessel composting. Int Biodeterior Biodegrad 61:357-364 (2008).

54 Eisentraeger A, Hund-Rinke K and Roembke J, Assessment of ecotoxicity of contaminated soil using bioassays, in Manual for Soil Analysis - Monitoring and Assessing Soil Bioremediation, ed. by Margesin R and SchinnerF. Springer, Berlin/Heidelberg, Germany,pp.321-359 (2005).

55 Płaza G, Nalecz-Jawecki G, Ulfig K and Brigmon RL, The application of bioassays as indicators of petroleum-contaminated soil remediation. Chemosphere 59:289-296(2005).

56 Gustavino B, Caciolli S and Mancini L, Guideline of the micronucleus test in Vicia faba for the evaluation of mutagens in freshwaters and sediments. Roma: Istituto Superiore di Sanità (Rapporti ISTISAN 13/27) (2013). [Online]. Available: http://www. iss.it/binary/publ/cont/13_27_web.pdf [27 December 2015].

57 Cotelle S, Dhyevre A, Muller S, Chenon P, Manier N, Pandard P et al., Soil genotoxicity assessment: results of an interlaboratory study on the Vicia micronucleus assay in the context of ISO standardization. Environ Sci Pollut Res 22:988-995 (2015). 


\section{Figure legend}

Figure 1. Ergosterol concentration in the contaminated soil (CTRL) and during the treatment. T0 represents the time of mixing the soil with the SMS. (+) SMS, soil mixed with the SMS; (-) SMS, soil not mixed with the SMS. The (a) on the bars indicate values significantly different from the corresponding values in the CTRL at the $5 \%$ level $(P<0.05)$; the $(b)$ on the bars indicate values significantly different from the corresponding value at the previous time of analysis at the $5 \%$ level $(P<0.05)$.

Figure 2. DGGE analysis of the PCR amplified fungal ITS1 fragment obtained by the analysis of the metagenome of the microbial community characterizing the soil treated. CTRL, contaminated soil and during the treatment; T0 represents the time of mixing the soil with the SMS. T1 - T8 successive times of analysis. T8 $\mathrm{NM}$ contaminated soil after 8 months of incubation in the biopile not mixed with the SMS.

Figure 3. Fractional copy number of GN (Gram negative) and GP (Gram positive) PAH-RHD $\alpha$ transcripts in the treated soil at the different times of analysis. CTRL, contaminated soil; T0, represents the time of mixing the soil with the SMS. The (a) on the bars indicate values significantly different from the corresponding values in the CTRL at the 5\% level $(P<0.05)$; the (b) on the bars indicate values significantly different from the corresponding value at the previous time of analysis at the $5 \%$ level $(P<0.05)$.

Figure 4. Fractional copy numbers of bacterial taxa at different times of analysis. The $\left(^{*}\right)$ on the bars indicate values significantly different from the corresponding values the previous time of analysis at the 5\% level $(P<$ 0.05). CTRL, contaminated soil; T0, represents the time of mixing the soil with the SMS. All the fractional copy number values at the different times of analysis were significantly different from the corresponding values in the CTRL at the $5 \%$ level $(P<0.05)$. 
Table 1. Bacterial taxa and PAH-ring hydroxylating dioxygenases specific primers

\begin{tabular}{llccc} 
Target & \multicolumn{1}{c}{ Primers } & $\begin{array}{c}\text { Annealing } \\
\mathrm{T}\left({ }^{\circ} \mathrm{C}\right)\end{array}$ & $\begin{array}{c}\text { Efficiency } \\
(\%)\end{array}$ & Reference \\
\hline Gram positive & PAH-RHD $\alpha$ GPF/R & 54 & 97 & 22 \\
Gram negative & PAH-RHD $\alpha$ GNF/R & 57 & 94 & 22 \\
All groups & 341 F/534R & 60 & 93 & 23 \\
$\alpha$-Proteobacteria & Eub338/Alf685 & 60 & 100 & 24 \\
$\beta$-Proteobacteria & Enb338/Bet680 & 55 & 96 & 25 \\
Acidobacteria & Acid31/Eub518 & 55 & 94 & 26 \\
Actinobacteria & Actino235/Eub518 & 60 & 90 & 27 \\
Bacteroidetes & Cfb319/Eub518 & 60 & 95 & 28 \\
Firmicutes & Lgc353/Eub518 & 55 & 95 & 29 \\
\hline
\end{tabular}

Amplification efficiency, the percentage of template that was amplified in each PCR cycle:

Efficiency $=(E-1) \times 100 \%$, $E$ is calculated from the slope of the standard curve using the formula $\mathrm{E}=10^{-1 / \text { slope }}$.
Table 3. Shannon Weaver Index $\left(\mathrm{H}^{\prime}\right)$ and evenness (E) values of fungal communities at successive time of experiment in the biopile mixed with the SMS

\begin{tabular}{lcc} 
& $H^{\prime}$ & $E$ \\
\hline CTRL & $2.91 \pm 0.03^{\mathrm{a}}$ & $0.92 \pm 0.05^{\mathrm{a}}$ \\
T0 & $2.32 \pm 0.07^{\mathrm{b}}$ & $0.89 \pm 0.03^{\mathrm{b}}$ \\
T1 & $2.89 \pm 0.05^{\mathrm{a}}$ & $0.92 \pm 0.05^{\mathrm{a}}$ \\
T2 & $2.86 \pm 0.07^{\mathrm{a}}$ & $0.93 \pm 0.03^{\mathrm{a}}$ \\
T3 & $2.43 \pm 0.04^{\mathrm{c}}$ & $0.88 \pm 0.02^{\mathrm{b}}$ \\
T4 & $2.52 \pm 0.06^{\mathrm{C}}$ & $0.89 \pm 0.04^{\mathrm{b}}$ \\
T5 & $3.01 \pm 0.07^{\mathrm{d}}$ & $0.94 \pm 0.05^{\mathrm{c}}$ \\
T6 & $2.99 \pm 0.03^{\mathrm{d}}$ & $0.96 \pm 0.04^{\mathrm{c}}$ \\
T7 & $2.60 \pm 0.06^{\mathrm{e}}$ & $0.89 \pm 0.05^{\mathrm{b}}$ \\
T8 & $2.75 \pm 0.04^{\mathrm{f}}$ & $0.91 \pm 0.06^{\mathrm{a}}$ \\
T8NM & $2.92 \pm 0.05^{\mathrm{a}}$ & $0.91 \pm 0.07^{\mathrm{a}}$
\end{tabular}

CTRL; contaminated soil; T8 $8^{\mathrm{NM}}$ values marked with the same letter are not statistically different $(P<0.05)$.

\begin{tabular}{|c|c|c|c|c|}
\hline & Water & $\begin{array}{c}\text { Soil } \\
\text { elutriate }\end{array}$ & $\begin{array}{c}\text { Soil } \\
\text { elutriate } \\
\text { T8 (Biopile } \\
\text { no SMS) }\end{array}$ & $\begin{array}{c}\text { Soil } \\
\text { elutriate T8 } \\
\text { (Biopile } \\
\text { with SMS) }\end{array}$ \\
\hline Mitotic index (\%) & $14.2 \pm 1.2^{\mathrm{a}}$ & $13.6 \pm 0.4^{\mathrm{a}}$ & $13.4 \pm 0.9^{\mathrm{a}}$ & $9.8 \pm 0.6$ \\
\hline Aberration index (\%) & $0.4 \pm 0.03$ & $0.8 \pm 0.03^{b}$ & $0.9 \pm 0.02^{b}$ & $2.7 \pm 0.4$ \\
\hline MNC/100cell & $0.2 \pm 0.01$ & $3.9 \pm 0.3^{c}$ & $4.2 \pm 0.8^{c}$ & $12.5 \pm 1.8$ \\
\hline
\end{tabular}

Soil elutriate, elutriate from the contaminated soil at the beginning of the experiment; Biopile no SMS, the dynamic biopile not mixed with the SMS; MNC, micronulei; values marked with the same letters are not statistically diverse $(P<0.05)$.

Table 2. PAH concentrations and percentage of degradation in pilot plant biopile mixed with the SMS at the beginning of the experiment (T0) and monthly for the 8 months of experiment (T1 - T8)

$\begin{array}{lllllllll}\text { T0 } & \text { T1 } & \text { T2 } & \text { T3 } & \text { T4 } & \text { T5 } & \text { T6 } & \text { T7 } & \text { T8 }\end{array}$

\begin{tabular}{|c|c|c|c|c|c|c|c|c|c|}
\hline & $\mathrm{mg} \mathrm{kg}^{-1}$ & $\mathrm{mg} \mathrm{kg}^{-1}$ & $\mathrm{mg} \mathrm{kg}^{-1}$ & $\mathrm{mg} \mathrm{kg}^{-1}$ & $\mathrm{mg} \mathrm{kg}^{-1}$ & $\mathrm{mg} \mathrm{kg}^{-1}$ & $\mathrm{mg} \mathrm{kg}^{-1}$ & $\mathrm{mg} \mathrm{kg}^{-1}$ & $\mathrm{mg} \mathrm{kg}^{-1}$ \\
\hline \multicolumn{10}{|l|}{2 condensed rings } \\
\hline Naphthalene & $23.0 \pm 3.0$ & $5.0 \pm 1.0$ & $6.5 \pm 1.2$ & $2.4 \pm 1.2$ & $<5$ & $<5$ & $<5$ & $<5$ & $<5$ \\
\hline \multicolumn{10}{|l|}{3 condensed rings } \\
\hline Acenaphthylene & $11.5 \pm 1.7$ & $13.1 \pm 2.0$ & $3.9 \pm 1.1$ & $3.0 \pm 1.0$ & $8.8 \pm 2.1$ & $1.1 \pm 0.2$ & $1.3 \pm 0.2$ & $1 \pm 0.2$ & $6.5 \pm 0.5$ \\
\hline Acenaphthene & $72.5 \pm 6.4$ & $43.7 \pm 3.2$ & $5.1 \pm 2.0$ & $2.2 \pm 0.6$ & $1.2 \pm 0.5$ & $<5$ & $<5$ & $<5$ & $<5$ \\
\hline fluorene & $110.9 \pm 12.7$ & $122.7 \pm 10.9$ & $41.2 \pm 3.3$ & $20.1 \pm 1.7$ & $17.5 \pm 1.2$ & $<5$ & $2.1 \pm 0.2$ & $1.8 \pm 0.3$ & $<5$ \\
\hline Phenanthrene & $508.4 \pm 43.7$ & $322.9 \pm 18.0$ & $95.4 \pm 7.9$ & $76.1 \pm 4.6$ & $60.8 \pm 4.3$ & $<5$ & $6.7 \pm 0.3$ & $3.8 \pm 0.3$ & $<5$ \\
\hline Anthracene & $2557.0 \pm 243.5$ & $1365.2 \pm 10.5$ & $815.4 \pm 7.9$ & $751.2 \pm 6.2$ & $719.5 \pm 6.2$ & $4.4 \pm 1.2$ & $10.8 \pm 1.0$ & $74.6 \pm 4.1$ & $13.3 \pm 0.4$ \\
\hline \multicolumn{10}{|l|}{4 condensed rings } \\
\hline Fluoranthene & $873.2 \pm 76.1$ & $371 . \pm 2.91$ & $204.9 \pm 10.7$ & $152.6 \pm 12.1$ & $151.0 \pm 11.2$ & $9.4 \pm 3.1$ & $18.6 \pm 1.2$ & $11.3 \pm 1.2$ & $9.9 \pm 0.5$ \\
\hline Pyrene & $610.3 \pm 47.9$ & $232.9 \pm 2.8$ & $200.0 \pm 3.2$ & $195.2 \pm 14.2$ & $191.6 \pm 16.4$ & $14.0 \pm 1.0$ & $12.4 \pm 0.9$ & $13.5 \pm 2.1$ & $8.4 \pm 0.5$ \\
\hline benzo a antrhracene & $150.7 \pm 13.8$ & $66.3 \pm 4.3$ & $46.1 \pm 3.0$ & $30.6 \pm 2.8$ & $26.7 \pm 1.9$ & $13.9 \pm 0.2$ & $10.8 \pm 0.5$ & $5.5 \pm 0.9$ & $10.3 \pm 0.6$ \\
\hline Chrysene & $157.2 \pm 13.9$ & $74.3 \pm 6.0$ & $58.3 \pm 4.3$ & $36.9 \pm 1.7$ & $33.3 \pm 1.7$ & $17.3 \pm 0.4$ & $13.6 \pm 0.9$ & $7.2 \pm 0.6$ & $8.8 \pm 0.5$ \\
\hline \multicolumn{10}{|l|}{5 condensed rings } \\
\hline Benzo $b$ fluoranthene & $144.2 \pm 12.3$ & $20.0 \pm 1.1$ & $34.7 \pm 4.5$ & $13.5 \pm 0.9$ & $<5$ & $28.8 \pm 1.2$ & $19.3 \pm 1.2$ & $3.3 \pm 0.3$ & $<5$ \\
\hline Benzo k fluorantene & $14.5 \pm 1.1$ & $14.1 \pm 1.1$ & $<5$ & $<5$ & $<5$ & $6.7 \pm 0.9$ & $<5$ & $1.2 \pm 0.2$ & $28.7 \pm 0.5$ \\
\hline Benzo a pyrene & $98.6 \pm 7.8$ & $<5$ & $<5$ & $76.8 \pm 6.1$ & $74.1 \pm 1.2$ & $13.9 \pm 1.0$ & $10.5 \pm 1.3$ & $4.1 \pm 0.6$ & $17.1 \pm 0.4$ \\
\hline Dibenzo a,h anthracene & $<5$ & $<5$ & $<5$ & $<5$ & $<5$ & $3.7 \pm 0.4$ & $<5$ & $0.8 \pm 0.1$ & $1.9 \pm 0.5$ \\
\hline \multicolumn{10}{|l|}{6 condensed rings } \\
\hline Benzo g,h,i pirylene & $<5$ & $<5$ & $<5$ & $<5$ & $<5$ & $6.9 \pm 1.7$ & $6.8 \pm 1.4$ & $1.7 \pm 0.2$ & $6.1 \pm 0.5$ \\
\hline Indeno 1,2,3-cd pyrene & $61.9 \pm 5.4$ & $13.0 \pm 1.5$ & $<5$ & $<5$ & $<5$ & $9.2 \pm 2.1$ & $6.8 \pm 0.9$ & $2.1 \pm 0.1$ & $1.4 \pm 0.5$ \\
\hline \multirow[t]{5}{*}{$\Sigma$ PAHs } & $5393.9 \pm 489.3$ & $2664.3 \pm 65.4$ & $1511.5 \pm 49.1$ & $1360.6 \pm 53.1$ & $1284.5 \pm 17.9$ & $129.3 \pm 13.4$ & $119.7 \pm 10$ & $131.9 \pm 11.2$ & $112.4 \pm 5.4$ \\
\hline & & $\%$ depl & $\%$ depl & $\%$ depl & $\%$ depl & $\%$ depl & $\%$ depl & $\%$ depl & $\%$ depl \\
\hline & & T1-T0 & $\mathrm{T} 2-\mathrm{T} 0$ & T3-T0 & T4-T0 & T5-T0 & T6-T0 & T7-T0 & T8-T0 \\
\hline & & $\Sigma$ PAHs & $\Sigma$ PAHs & $\Sigma$ PAHs & $\Sigma$ PAHs & $\Sigma$ PAHs & $\Sigma$ PAHs & $\Sigma$ PAHs & $\Sigma$ PAHs \\
\hline & & 50.6 & 72 & 74.8 & 76.2 & 97.6 & 97.8 & 97.6 & 97.9 \\
\hline
\end{tabular}

$\mathrm{SD}$, standard deviation 


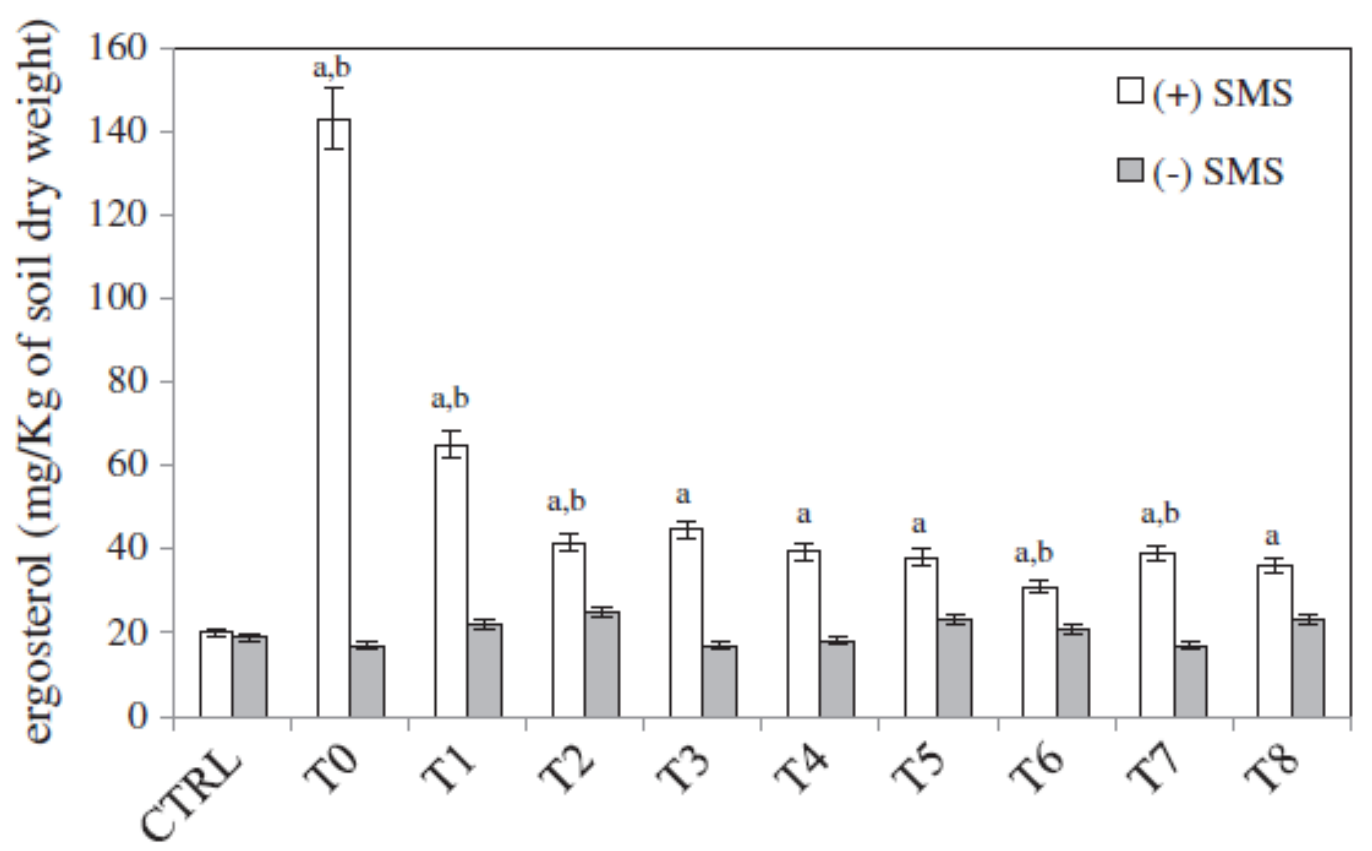

Figure 1

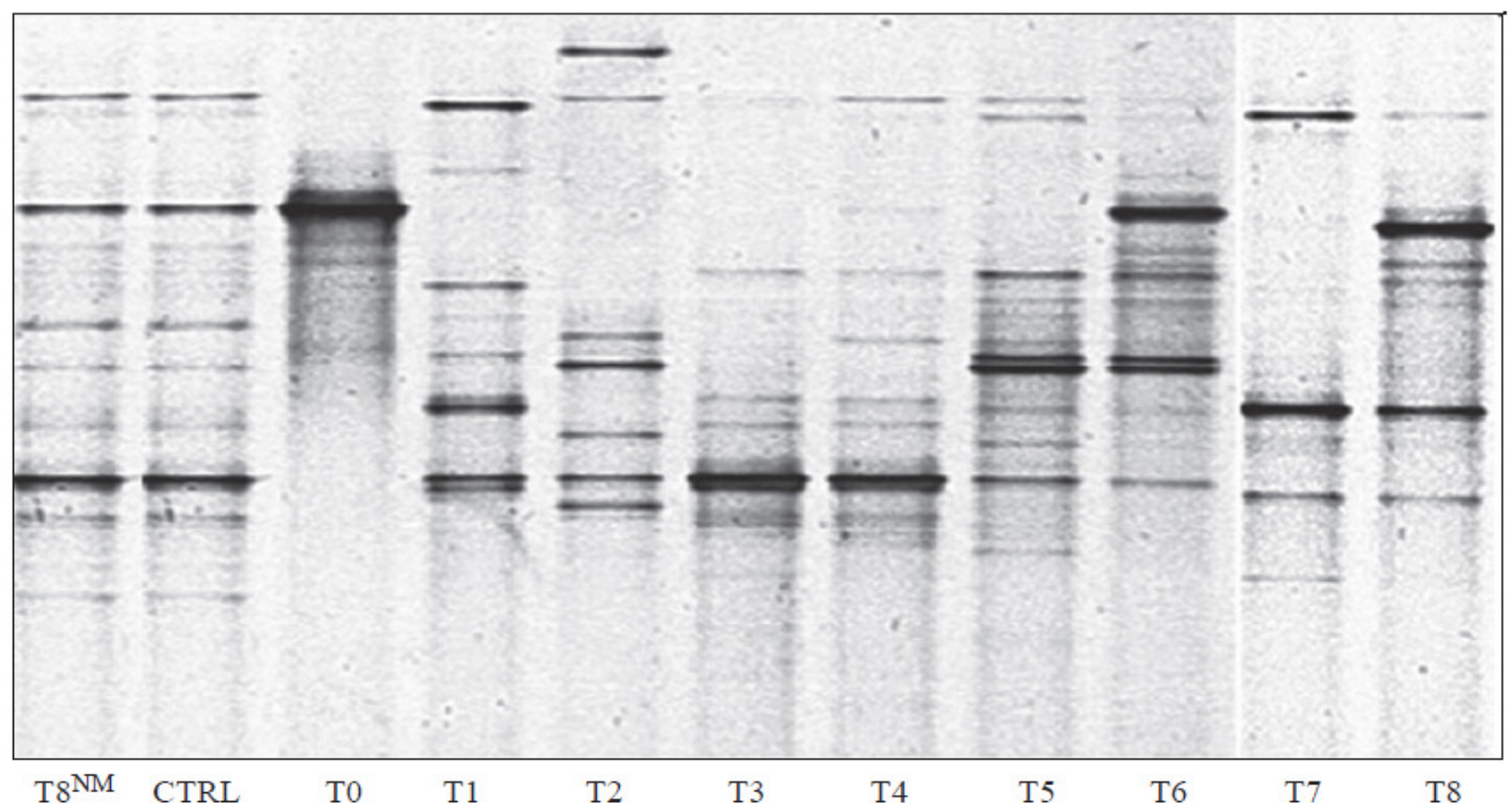

Figure 2 


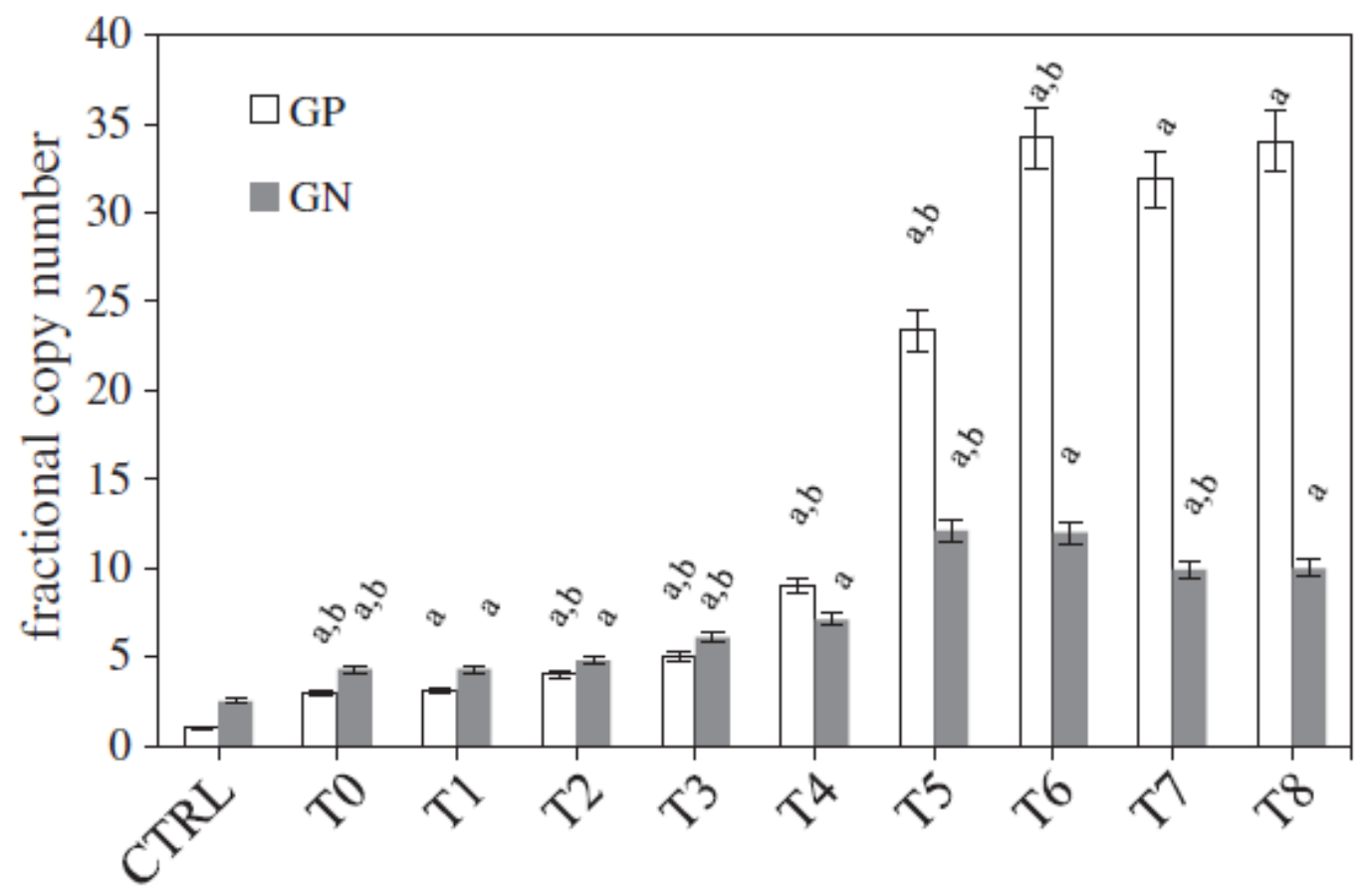

Figure 3

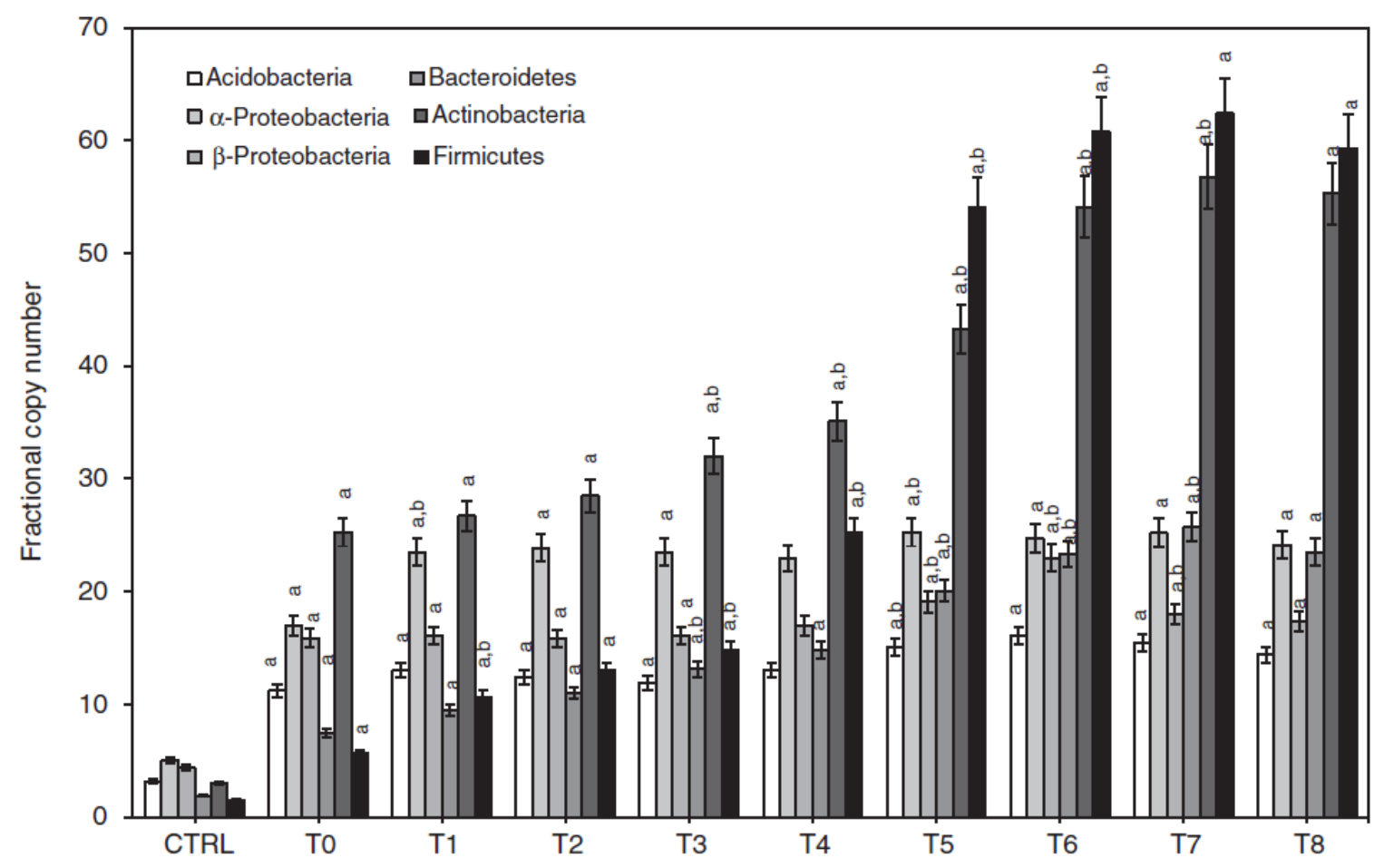

Figure 4 